\title{
CAPOEIRA NA EDUCAÇÃO FÍSICA: PERSPECTIVAS DE EDUCAÇÃO INTEGRAL
}

\author{
CAPOEIRA IN PHYSICAL EDUCATION: PERSPECTIVES \\ OF INTEGRAL EDUCATION.
}

\section{CAPOEIRA EN EDUCACIÓN FÍSICA: PERSPECTIVAS DE EDUCACIÓN INTEGRAL.}

Ivo RibeIro DE SÁ ${ }^{1}$

SAMila ZAMBetTI dos SANTOS II 'Universidade Municipal de São Caetano do Sul (USCS), São Caetano do Sul/ SP- Brasil "Universidade Municipal de São Caetano do Sul (USCS), São Caetano do Sul/ SP- Brasil

Resumo Este artigo é resultado de uma pesquisa exploratória, oriunda de dissertação de mestrado, que investigou como a Capoeira pode contribuir para uma prática de Educação Integral no ambiente escolar. Tivemos como objetivo identificar as possibilidades pedagógicas da Capoeira. Para alcançar esse objetivo foram identificados nos discursos dos mestres de Capoeira aspectos relacionados à formação integral das pessoas. A partir disso, por um processo de transposição didática (BROSSEAU, 2008), foi elaborada uma proposta de formação de professores que contemplasse estes aspectos. Tomamos como pressuposto à teoria da complexidade como matriz epistemológica. Para tanto, entrevistamos mestres de Capoeira da região do Grande ABCDM/SP para alcançar aspectos do senso comum presentes no discurso destes e por meio da análise de conteúdo identificamos conceitos que convergem sobre aspectos que promovem o desenvolvimento integral do Ser Humano. Os pontos encontrados foram: aspectos integrativos das dimensões humanas da Capoeira e formação Integral do sujeito, a roda de Capoeira e a materialização das dimensões do sujeito e, por fim, a musicalidade e a historicidade da Capoeira, identificando o caráter histórico-social e cultural da mesma, que nos auxiliou na proposição de uma formação de professores, num caráter de superação e valorização da cultura brasileira visando à superação de conteúdos eurocêntricos, elitistas e esportivistas na prática da Educação Física na escola.

Palavras-chave: Capoeira; Formação integral do sujeito; Complexidade; EducaÇão InTEGral; EducaÇão Física; 
ABSTRACT This article is the result of an exploratory research from a master's dissertation that investigated how Capoeira can contribute to a practice of Integral Education in the school environment. We aimed to identify the pedagogical possibilities of Capoeira. To achieve this objective, aspects related to the integral formation of people were identified in the Capoeira masters' speeches. From this, through a process of didactic transposition (BROSSEAU, 2008), a proposal for teacher education that elaborated these aspects was elaborated. We assume the theory of complexity as an epistemological matrix. To this end, we interviewed Capoeira Masters from the Greater ABCDM / SP region to reach common sense aspects present in their discourse and through content analysis we identified concepts that converge on aspects that promote the integral development of the Human Being. The points found were: integrative aspects of Capoeira's human dimensions and Integral formation of the subject, the Capoeira wheel and the materialization of the subject's dimensions and, finally, Capoeira's musicality and historicity, identifying the historical, social and cultural character. of the same, which helped us in the proposition of a formation of teachers, in a character of overcoming and valorization of the Brazilian culture aiming at the overcoming of eurocentric, elitist and sportivist contents in the practice of the Physical Education in the school.

Keywords: Capoeira. Integral formation of the subject. Complexity. Integral Education. Physical Education.

RESUMEN Este artículo es el resultado de una investigación exploratoria de una disertación de maestría que investigó cómo Capoeira puede contribuir a una práctica de Educación Integral en el entorno escolar. Nuestro objetivo era identificar las posibilidades pedagógicas de la capoeira. Para lograr este objetivo, se identificaron aspectos relacionados con la formación integral de las personas en los discursos de los maestros de Capoeira. A partir de esto, a través de un proceso de transposición didáctica (BROSSEAU, 2008), se elaboró una propuesta de formación docente que elaboró estos aspectos. Asumimos la teoría de la complejidad como una matriz epistemológica. Con este fin, entrevistamos a Maestros de Capoeira de la región del Gran ABCDM / SP para alcanzar los aspectos de sentido común presentes en su discurso y a través del análisis de contenido identificamos conceptos que convergen en aspectos que promueven el desarrollo integral del Ser Humano. Los puntos encontrados fueron: aspectos integradores de las dimensiones humanas de Capoeira y la formación integral del sujeto, la rueda de Capoeira y la materialización de las dimensiones del sujeto y, finalmente, la musicalidad e historicidad de Capoeira, identificando el carácter histórico, social y cultural. de lo mismo, que nos ayudó en la propuesta de una formación de docentes, en un carácter de superación y valorización de la cultura brasileña con el objetivo de superar los contenidos eurocéntricos, elitistas y deportivos en la práctica de la Educación Física en la escuela.

Palabras Claves: Capoeira; Formación integral del sujeto; Complejidad; EducaciÓN INTEGRAL; EDUCACIÓN FÍSICA; 


\section{INTRODUÇÃo}

A partir da minha trajetória como professora de Educação Física no ensino público de municípios do $\mathrm{ABCDM}$, e a partir da minha vivência na Capoeira desde que nasci, pude observar que a escola ainda vive uma educação fragmentada e cartesiana, e que a capoeira pode ser um mecanismo pedagógico diferenciado para superar essa visão cartesiana e fragmentada de sujeito e também superar fazeres esportivistas na Educação Física.

Nessa perspectiva entende-se que a Capoeira como conteúdo escolar pode contribuir para o desenvolvimento integral do ser humano, pois atua de maneira direta e indireta sobre todos os aspectos humanos mobilizando as dimensões sociais, culturais, intelectuais, emocionais e físicas.

Sua essência adentra a esfera do movimento do "homem consigo mesmo, do homem com o mundo e do homem com os outros" que passa assim a configura-se como Motricidade Humana (FEITOSA, 1999) o que pode levar os alunos aprender a viver no mundo.

Nesse sentido, sua inserção no contexto educacional não procura formar capoeiristas e sim que se promova uma educação que leve o sujeito a ler sua realidade, interpretá-la e modificá-la na medida em que reflete sobre o todo.

Para tanto, este estudo buscou investigar como a Capoeira pode contribuir para uma visão de Educação Integral no ambiente escolar.

Assim, identificar e socializar as possibilidades pedagógicas da Capoeira como uma prática integrativa dos aspectos humanos na busca de uma formação integral do sujeito é nosso objetivo, e para tanto buscamos nos discursos dos Mestres de Capoeira elementos que nos pudessem auxiliar para a proposição da capoeira como um conteúdo educacional através da transposição didática dos resultados encontrados na pesquisa e inseridos em uma formação de professores.

Nesse sentido, este estudo subsidiou a construção de uma formação para professores com o objetivo de lhes dar subsídios para trabalhar com a Capoeira enquanto conteúdo da área em suas aulas.

Esta formação tomou como base a técnica da teoria das situações didáticas (BROSSEAU, 2008)para que os elementos da capoeira possam ser trabalhados de maneira organizada.

Além disso, busca-se com essa formação a superação de uma visão dicotomizada de formação humana. Nesse sentido, considera a visão integral de formação do sujeito que entende que a sociedade possui uma estrutura complexa, em meio a uma infinita teia onde tudo está interligado e conectado dando sentido e forma a nossa realidade, a como vivemos, pensamos, reagimos, aprendemos, sentimos, enfim, como habitamos no mundo (MORIN, 2004).

Não foi intenção deste estudo instrumentalizar os leitores a forma prática como se inseriria a capoeira na escola. Trouxemos nesta pesquisa subsídios teóricos para balizar as ações pedagógicas e como produto final da dissertação uma formação de professores para aí sim, formar praticamente os que vivenciarem a formação.

Assim, esse artigo expõe o percurso e o produto da dissertação de mestrado realizado no período de 2017-2019. 


\section{CAPOEIRA: UM CONTEÚdO DA EDUCAÇÃo FÍSICA}

Atualmente, vemos despontar a Capoeira como esporte genuinamente brasileiro e promotorde novos elementos de discussão de uma atividade física que proporciona educação, cultura, saúde e qualidade de vida. A Capoeira possui tais valores, por ser uma expressão corporal que envolve dança, luta, cânticos, palmas, músicas, relacionamentos interpessoais, força, agilidade, coordenação e condicionamento físico, sendo citada por alguns autores (FALCÃO 1996; ZULU 1995; SILVA 2001) como oportuna proposta da Educação Física em vista dos seus compromissos com o bem estar biopsicossocial dos seus participantes, como diz Campos:

A Capoeira é uma excelente atividade física e é de uma riqueza sem precedentes para ajudar na formação integral do aluno. Ela atua de maneira direta e indireta sobre todos os aspectos: cognitivo, afetivo e motor. (CAMPOS, 2001, p. 25)

Sabemos que a Capoeira, além de esporte, arte, jogo, dança e filosofia de vida, é um conteúdo histórico-cultural da humanidade.

A Capoeira possui uma riqueza natural de movimentos corporais que traz em si elementos que justificam sua utilização como meio e objetivo da Educação Física e, ainda, na consolidação dos compromissos desta área através dos valores, conceitos, cooperação e manutenção da saúde.

Além disso, a capoeira segundo alguns autores (CAMPOS, 2001; FALCÃO 1996; ZULU 1995; SILVA 2001)pode ser entendida como um patrimônio cultural brasileiro e reconhecida como patrimônio imaterial do povo brasileiro pelo Instituto do Patrimônio Histórico e Artístico Nacional (2008), com especificidade ímpar pela sua multiplicidade e sua abrangência, não devendo ser tratada unidimensionalmente, isto é, só esporte, só jogo, só luta, só dança e etc. Deve-se procurar relacionar cada uma de suas interfaces para não simplificá-la e reduzi-la em seu contexto global, pois o seu universo somente pode ser entendido a partir da análise do conjunto de suas dimensões: antropológica, sociológica, técnica, estética e artística.

A partir das discussões teóricas, até aqui realizadas, foi possível fazer uma proposta que busque a formação integral do sujeito, abordando a Capoeira numa perspectiva pedagógica envolvendo os diversos ritmos, a coordenação motora, a noção de tempo e espaço, a criatividade, a expressão corporal, sem padrões a serem seguidos e, ainda, proporcionar estímulos para a expressão das singularidadesno espaço coletivo.

Entretanto, para fundamentar a proposta de maneira significativa no campo da Educação Física se fez necessário considerar a Pluralidade Cultural e suas interferências no contexto escolar, uma vez que a Pluralidade Cultural constitui uma temática relevante no campo da educação, sobretudo, pelo seu caráter democrático e abrangente, pois se aproxima do multiculturalismo.

As diversas culturas imersas na sociedade deverão estar representadas nos objetivos gerais nos diferentes componentes curriculares, inclusive na Educação Física Escolar, orientando o aprendizado dos estudantes para

[...]conhecer, valorizar, respeitar e desfrutar da pluralidade de manifestações de cultura corporal do Brasil e do mundo, percebendo-as como recurso valio- 
so para a integração entre as pessoas e entre diferentes grupos étnicos (BRASIL, 1998, p.63).

Nesse sentido, o reconhecimento do outro se faz necessário para haja a integração entre as pessoas, pois é por meio da valorização do diálogo entre as culturas que se estimula a boa convivência e se estimula o aprendizado para que se possa apreciar as diversidades existentes nas múltiplas esferas das relações sociais.

$\mathrm{Na}$ Base Nacional Comum Curricular encontramos que

É fundamental frisar que a Educação Física oferece uma série de possibilidades para enriquecer a experiência das crianças, jovens e adultos na Educação Básica, permitindo o acesso a um vasto universo cultural" (BRASIL, 2017, p. 211)

Dos variados conteúdos que a Educação Física pode contemplar (conhecimentos do corpo, esporte, jogos, lutas, ginásticas, danças, atividades rítmicas e expressivas e práticas corporais de aventura), o tema pluralidade deve estar presente para a discussão e reflexão sobre o respeito às diferenças humanas, e a Capoeira é um conteúdo propício para esta discussão uma vez que a capoeira é composta por gestualidade, simbolismo, interações além de valores de uma manifestação integrante do "alento da alma do povo brasileiro, e que, em determinado momento da história, o Estado negou ao povo o direito à vivência operativa da Capoeira" (ZULU, 1995, p.20).

A esse respeito, vale ressaltar que a Educação Física, como as outras disciplinas, deve procurar enfocar questões que tratam das diferenças humanas comunicadoras de uma cultura Interétnicafruto de um entrelaçamento cultural.

Nesse sentido, os professores de Educação Física, assim como os professores de outras disciplinas, devem estar conscientes e convictos de que um de seus papeis é

[...] romper com a cultura oficial, mudar a mentalidade em direção a uma consciência de classe para que a professora ou o professor possa compreender-se como ser social, para que supere o senso comum e, concomitantemente, altere tanto as suas relações de trabalho quanto as condições objetivas da prática educativa. Mas, para isso, é preciso saber ouvir e se dispor a ouvir o que seu aluno tem a dizer a respeito de si mesmo e do outro que com ele partilha a vida, partilha o dia-a-dia, incluindo o próprio professor. (GUSMÃO, 2000, p.18).

Assim, a escolha dos conteúdos é de extrema importância para uma possível transformação do universo escolar onde a sociedade está inserida.

A Capoeira, como os demais conteúdos, necessita de novo olhar sobre a metodologia para a sua melhor inserção, prática, valores e conceitos que poderão estar presentes como conteúdo pedagógico da disciplina procurando proporcionar muitas possibilidades de compreensão e construção do conhecimento.

Contudo, a Capoeira, como uma das possibilidades pedagógicas na Educação Física, pode vir a contribuir para o desenvolvimento integral do humano, pois foi por meio desta pluralidade de distintas manifestações e entrecruzamentos culturais que a mesma originou e proporcionou a diversidade de instrumentos musicais e a pluralidade étnica de seus par- 
ticipantes. Estes temas podem ser abordados de acordo com vivências e reflexões sobre a história e filosofia de vida da Capoeira no âmbito escolar.

A partir dessas reflexões, conseguimos perceber as significações e relevâncias que a Capoeira proporcionará aos alunos nas aulas Educação Física de acordo com as suas vertentes e possibilidades pedagógicas. É possível trabalhar com este conteúdo por meio de distintas estratégias desde que os profissionais atuantes procurem legitimar a Capoeira como instrumento de educação que colabore com a visão ampliada de um processo educacional crítico, reflexivo e contextualizado, com os ideais de promoção da cidadania do sujeito, conforme a preocupação de alguns autores analisados como Zulu (1995).

Para tanto, o professor deve dominar alguns conhecimentos básicos da Capoeira para que a Capoeira tenha seu papel desempenhado de forma que consiga interferir desenvolvimento integral do sujeito.

\section{Procedimentos Metodológicos}

A construção do referencial teórico-metodológico que serviu de base para a estruturação desta pesquisa se constituiu a partir da teoria da complexidade, de estudos que discutem a Educação, a área de Educação Física e a Capoeira, numa perspectiva Crítico-dialética.

Assim, para explorar o problema "Como a Capoeira pode contribuir para uma visão de Educação Integral?” entende-se que a análise de conteúdo se mostrou adequado para essa pesquisa.

\section{O Campo}

O campo de investigação desta pesquisa foi o universo da Capoeira no que tange o conhecimento dessa manifestação expressado pelos mestres. Para tal, as entrevistas buscaram entender como os mestres pensam a atuação da capoeira na formação do sujeito.

Essa busca nos ajudou a identificar a atuação da capoeira nas várias dimensões do humano em suas raízes e trazer para o contexto educacional, de maneira que essa manifestação, quando abordada pelo professor de Educação Física, consigatrazer os conhecimentos da Cultura popular para o ambiente escolar, de forma sistematizada e sem perder suas origens históricas e culturais.

\section{Os Sujeitos}

Nossos sujeitos são mestres de Capoeira que foram escolhidos para serem entrevistados com os seguintes critérios: Atuarem no ensino da Capoeira. Aceitarem participar da entrevista. Serem de diferentes cidades da região do Grande ABCDM, que é onde a dissertação está sendo desenvolvida; já terem atuado como mestres de Capoeira em diferentes locais. Os Mestres que estavam de acordo com o perfil e aceitaram participar da pesquisa são das seguintes cidades: Santo André, São Caetano e Mauá,

Esses critérios nos possibilitaram trazer para a transposição didática maior riqueza quanto à diversidade da Capoeira para que suas características históricas e culturais permaneçam presentes quando ensinadas no ambiente escolar. 


\section{Os procedimentos de elaboração dos instrumentos de coleta de dados.}

Como instrumento de coleta de dados, utilizamos entrevistas semiestruturada. Construímos um roteiro de entrevista a partir do problema desta pesquisa, de todo o referencial teórico e dos objetivos específicos. Este roteiro procurou identificar indícios de formação integral de sujeito, aspectos práticos da capoeira, as relações entre a capoeira e a formação do sujeito. Os temas utilizados para orientar o Roteiro foram Formação Humana seguido das dimensões Física, Emocional, Intelectual, Cultural e Social.

Após a elaboração do roteiro a entrevista passou por uma pré-testagem para que garantir a fidedignidade do instrumento e readequação das questões do roteiro definitivo. As entrevistas aconteceram entre outubro de 2018 e dezembro de 2018. Foram individuais e gravadas em áudio como segue: Mestre de Diadema- 09/2018 (entrevista teste), Mestre de Mauá- 10/2018, Mestre de São Caetano Do Sul- 11/2018 e Mestre de Santo André- 12/2018.

\section{Os Procedimentos de análise}

A análise partiu de temas advindos da literatura. Estes temas são: a dimensão emocional, a dimensão intelectual, a dimensão física, a dimensão social, a dimensão cultural, e a formação humana.

Utilizamos como procedimento a análise de conteúdo que tem como base o conteúdo manifesto e explícito onde o ponto de partida para identificação do conteúdo manifesto é o que está escrito, por isso a transcrição de todos os áudios.

Após entrevistas transcritas, para fim de visualização das respostas, construímos tabelas com os temas citados acima que, nesse momento, elencamos como nossas Unidades de Registro, num total de seis tabelas. Compomos a tabela de forma que conseguíssemos identificar e relacionar as mensagens com cada Unidade de Registro e, deste ponto, realizamos a inferência uma a uma. Em sequência a essa etapa foram criadas categorias a posteriori, aproveitando toda a riqueza encontrada nas entrevistas, e após esse trabalho de "garimpo" dentro das entrevistas transcritas, concentramos os temas em três categorias.

A primeira categoria, denominada "Aspectos integrativos das dimensões humanas da Capoeira e Formação Integral do sujeito" discute aspectos integrativos das dimensões que constituem o ser humano que a capoeira oferece, além das contribuições educacionais que esses aspectos trazem. A segunda categoria, denominada de "A roda de Capoeira e a materialização das dimensões do sujeito" aborda a Roda de Capoeira como um espaço capaz de integrar as dimensões que compõem o ser humano e a terceira categoria "A Musicalidade e a historicidade da Capoeira" contempla os aspectos relativos a roda de Capoeira e a musicalidade que se mostraram significativos nos discursos dos sujeitos quando falavam da música e da história do povo negro no Brasil.

A partir da interpretação destas categorias buscamos conceitos que pudessem contribuir para a formulação de um plano de formação de professores

Nesse artigo, achamos importante trazer trechos da discussão e análise de dados para contribuir com o entendimento das categorias criadas na análise de dados e no contexto da formação de professores formulada a partir de toda a pesquisa. 


\section{DiscuSSÃo E ANÁLISE DE DADOS}

Antes de dar início à análise propriamente dita consideramos importante realizar um breve relato a respeito dos sujeitos da pesquisa.

Mestre A e C aprenderam Capoeira em São Paulo e Mestre M aprendeu capoeira no interior da Bahia e relata que, ao vir morar em São Paulo, ele mesmo retirou sua graduação de formado e começou da primeira graduação com um Mestre de São Paulo.

Todos aprenderam capoeira entre os 10 e 15 anos, quando as motivações para a praticar foram variadas. Mestre $\mathrm{M}$ relata que não tinha opção, era a única coisa que tinha na sua cidade natal e que seus coleguinhas faziam capoeira e ele também foi fazer. Mestre $\mathrm{C}$ relata que foi buscar na Capoeira uma forma de ser mais eficiente em sua defesa, pois diz que era muito briguento e não queria apanhar e Mestre A relata que escolheu capoeira porque fazia parte do entorno de onde morava.

Todos os mestres relatam ensinar Capoeira "Paulista", mas sempre falam sobre Capoeira Angola e Regional como algo presente em sua didática.

Como já mencionado anteriormente dividimos a análise em categorias que pudessem subsidiar a construção da proposta de formação de professores. Nesse sentido, apresentamos a seguir a análise que cada uma destas categorias.

\section{Primeira categoria: Aspectos integrativos das dimensões humanas da capoeira e formação integral do sujeito}

Como a ideia desta pesquisa foi identificar as contribuições que a Capoeira pode trazer para a formação integral do sujeito e, daí, contribuir para uma educação integral na escola, partimos para a análise dos dados pela unidade que chamamos de aspectos integrativos das dimensões humanas da Capoeira e formação integral do sujeito.

Através da ideia trazida por Edgar Morin (2003) que entende que o ser humano é a um só tempo físico, biológico, psíquico, cultural, social e histórico, onde o sujeito deve se desenvolver tomando verdadeiramente conhecimento e consciência de sua identidade e possibilidades como todos os outros humanos nesta unidade complexa.

A ideia de Educação Integral está exatamente nessa busca, tendo como princípio, como encontramos em Guará

[...] a ideia filosófica de homem integral, realçando a necessidade de homem integrado de suas faculdades cognitivas, afetivas, corporais e espirituais, resgatando como tarefa prioritária da educação, a formação do homem, compreendido em sua totalidade (GUARÁ, 2006, p. 16).

Como na BNCC

[...]a Educação Básica deve visar à formação e ao desenvolvimento humano global, o que implica compreender a complexidade e a não linearidade desse desenvolvimento, rompendo com visões reducionistas que privilegiam ou a dimensão intelectual (cognitiva) ou a dimensão afetiva. (BRASIL, 2017, p.14).

Nesse sentido, os Mestres revelam em suas mensagens a possibilidade que a Capo- 
eira traz de exercício de todas essas faculdades do humano (cognitivas, afetivas, corporais e espirituais),principalmente evidenciadas na Roda de Capoeira, pois nela o sujeito está imerso em uma dinâmica onde seu corpo deve responder a estímulos diversos como relatado pelo Mestre $\mathrm{C}$.

No mesmo sentido, Mestre A fala: "Então a realidade do capoeira é essa, é o instrumento, é a roda, é a cantiga". Contribuindo com esta ideia o Mestre M acrescenta dizendo que o mestre ao entoar o cântico na roda manifesta valores étnico-culturais, filosóficos e mítico contidos na prática da capoeira.

A capoeira tem na sua mestiçagem o amálgama étnico- cultural, questões sociais, políticas, e ideológicas, diferentes momentos históricos, o que contribuiu, a nosso ver, para gerar essa diversidade dentro do próprio universo da Capoeira. (ARRUDA, 2014, p.22)

E é na roda de Capoeira, onde encontramos a junção de todas as especificidades da capoeira acontecendo a um só tempo, que identificamos a segunda unidade de análise

\section{Segunda categoria: a roda de Capoeira e a materialização das dimensões do sujeito.}

O Jogo da Capoeira é um momento crucial para a roda. A roda é toda formada para que aconteça o jogo. É o auge do capoeirista, é a pura expressão, é o que move toda a roda, mas, ao mesmo tempo, sem os outros elementos o jogo não acontece, ou não tem sentido. Arruda nos traz a dimensão do ato de jogar capoeira quando diz que

Todo Capoeirista ao entrar na roda entra num complexo jogo de relações humanas. Sabe que pode ser sobrepujado, pois há uma relação de acúmulo de experiências, aprendizado, memória, arquivo, um saber corporal. Trata-se de uma dialogação corporal, um jogo de perguntas e respostas corporais intencionais. (ARRUDA, 2014, p.76)

Nessa perspectiva, os mestres relatam a importância do jogo explicitando que neste há uma linguagem corporal contida.

Isto não passou desapercebido pela Base Nacional Comum Curricular que nos traz a mesma ideia quando se fala da Educação Física como componente curricular:

[...] as práticas corporais são textos culturais passíveis de leitura e produção. Esse modo de entender a Educação Física permite articulá-la à área de Linguagens, resguardadas as singularidades de cada um dos seus componentes, [...]. (BRASIL, 2017, p.212)

Dessa forma, a Capoeira pode ser considerada linguagem, assim como entendemos a Educação Física, que, na sua complexidade, pode contribuir para o desenvolvimento integral do ser humano, pois atua de maneira direta e indireta sobre todos os aspectos humanos dando sentido a cada ação, sua essência adentra à esfera do movimento do "homem consigo mesmo, do homem com o mundo e do homem com os outros" que passa assim a configurar-se como Motricidade Humana (FEITOSA, 1999) o que pode levar os alunos a aprenderem a viver no mundo, pois a intenção não é que saiam capoeiristas e sim que se formem enquanto Sujeitos que conseguem ler sua realidade, interpretá-la e modificá-la à medida em que refletem sobre o todo, como deveria ser toda ação pedagógica do Professor de Educação Física dentro da Escola. 
Assim, encontramos na BNCC

Cada prática corporal propicia ao sujeito o acesso a uma dimensão de conhecimentos e de experiências aos quais ele não teria de outro modo. A vivência da prática é uma forma de gerar um tipo de conhecimento muito particular e insubstituível e, para que ela seja significativa, é preciso problematizar, desnaturalizar e evidenciar a multiplicidade de sentidos e significados que os grupos sociais conferem às diferentes manifestações da cultura corporal de movimento" (BRASIL, 2017, p.212)

Assim, a Capoeira pode ser vista como uma prática integrativa das dimensões humanas, contribuindo com a educação, na busca de uma educação integral e no desenvolvimento pleno do sujeito, uma vez que engloba em sua estrutura

luta-dança-jogo, estética-esportiva, folclore-cultura, história- tradição, lazer-lúdico, filosofia-educação, teoria-prática, etc. Dimensões essas que estão juntas, ligadas, imbricadas umas às outras e não separadas. (ARRUDA, 2014, p.22)

Ainda preocupados sobre o papel educativo, mas agora com o foco educativo da Capoeira, a BNCC nos traz que

Ao brincar, dançar, jogar, praticar esportes, ginásticas ou atividades de aventura, para além da ludicidade, os estudantes se apropriam das lógicas intrínsecas (regras, códigos, rituais, sistemáticas de funcionamento, organização, táticas etc.) a essas manifestações, assim como trocam entre si e com a sociedade as representações e os significados que lhes são atribuídos. (BRASIL, 2017, p.218).

Assim, a Capoeira segue como proposta pedagógica humanizadora, cidadã, complexa, principalmente, que entende a diversidade cultural como conteúdo da Educação Física, superando as visões que, geralmente, são norteadas a partir de paradigmas mecanicistas, com conteúdo elitistas e eurocentristas.

Nessa mesma linha de pensamento de criação e recriação, a espontaneidade e a liberdade de expressão, quando o mestre A diz que "a Ginga, a própria ginga é Lúdico", pode até nos parecer vago, mas na verdade, traz para a discussão a importância da ginga na capoeira, e com ela a negaça, mandinga ou malícia, termos muito utilizados no universo da Capoeira.

Para Rego (1968, p.57) "a ginga é elemento fundamental. Da ginga é que saem os golpes de defesa e ataque, não só golpes comuns a todos os capoeiristas, como os pessoais e os improvisados na hora". Essa improvisação é o que motiva o Mestre A em dizer que a Capoeira é Lúdica, que a Ginga é lúdica, indo ao encontro do que afirmamos anteriormente. Para Alves,

para além da regularidade dos movimentos possíveis, a experiência da ginga se disfarça, se desloca e se transveste infinitamente. Há algo de transgressor na ginga que contesta e subverte a própria ideia de ginga, revelando sempre outra coisa a cada vez que se repete na experiência de movimento. Não é "à toa" que todos os outros movimentos da capoeira derivam da experiência da ginga. (ALVES, 2013, p.282). 
A ginga ultrapassa os limites de um simples movimento gerador dos demais movimentos para a característica principal da Capoeira, do jogo da Capoeira, da rítmica da Capoeira. Podemos arriscar a dizer que a Ginga é o que traz, une e materializa todo conhecimento de quem está nela. Colaborando novamente com essa ideia, a afirmação de Alves quando diz que a

[...] ginga foge da ordem da representação, pois, quando em ato, é pura presença, e como tal, não se conforma a um modelo sem antes prescindir da consistência que a constitui, na virtualidade dos acontecimentos na qual ela se dá como evento.(ALVES, 2011, p.90)

A ginga é a parte explícita da negaça, da mandinga, da malícia, pois é nela que a expertise do capoeirista é revelada. Esses termos são expressões que marcam o "ludibriar" herdado da época da escravidão para esconder a potencialidade da Capoeira nas suas diversas características e a própria necessidade do negro escravizado em esconder o que ele sabia para preservar sua identidade.

E essa identidade vive na Capoeira e revive através das músicas, dos instrumentos, da interação entre o jogo, a música e oritmo.

\section{Terceira categoria: a musicalidade e a historicidade da capoeira}

Uma informação importante, que é consenso na concepção dos mestres, refere-se à musicalidade da Capoeira, que classificamos como composta pelos instrumentos e Cantigas.

Para eles, as cantigas trazem vida à história do povo negro que, pela razão da escravidão, inventou a Capoeira em terras brasileiras.

Mestre C afirma: "[...] é uma coisa dos antepassados dela" e "faz porque fica sabendo do sofrimento que o índio teve que o negro teve o sofrimento que teve pra construir esse país né?!".Aqui, ele afirma a importância das pessoas aprenderem a Capoeira porque é coisa de seus antepassados, porque na capoeira, ela pode entender a identidade de nosso povo. Jána mensagem a seguir "Vou fazer porque eu vou tocar, porque eu vou cantar, porque eu vou conhecer a história do Brasil" e

\footnotetext{
Nessa mesma linha de pensamento Mestre M relata que ao praticar a capoeira há uma imersão histórica que perpassa música, o corpo e as formas de comunicação provocando um processo identitário que faz parte da constituição do povo brasileiro.
}

O Mestre A não afirma explicitamente que a musicalidade traz a história do Brasil, ou do negro no Brasil, mas identificamos que, quando ele expôs uma narrativa que gosta de fazer em apresentações com seus alunos, traz um exemplo prático do que os Mestres $\mathrm{C}$ e $\mathrm{M}$ relataram sobre a importância da musicalidade na Capoeira. Ele afirma fazer tal narrativa ao som do berimbau: Mestre A: "1540. Brasil colonial! Para o branco a era da riqueza! Para o Negro, pobreza, escravidão e tortura. Disfarçado numa dança, nascia à capoeira!”.

Vale ressaltar, numa tentativa de explicar um momento vivido e que é algo presente nos mestres e praticantes de Capoeira, o sentimento exposto quando o mestre declamou tal narrativa, os olhos brilhavam, seus braços mostravam um arrepio, e sua fala trêmula explicitava a emoção contida. 
Conseguimos ver exatamente tal afirmação nas falas dos nossos sujeitos de pesquisa expostas acima, além de identificar que essas cantigas são acompanhadas por instrumentos de diversas fontes, que caracterizam que a Capoeira foi concebida em terras brasileiras, como trouxemos em Tavares e Silva (2000, pág.11) quando afirmam que "capoeira não é um fenômeno cultural facilmente apreendido pela historiografia tradicional. Trata-se de atividade humana surgida espontaneamente." E Rego corrobora com essa ideia quando diz que

\footnotetext{
No caso da capoeira, tudo leva a crer seja uma invenção dos africanos no Brasil, desenvolvida por seus descendentes afro-brasileiros, tendo em vista uma série de fatores colhidos em documentos escritos e, sobretudo, no convívio e diálogo constante com os capoeiristas. (...) Portanto, a minha tese é a de que a capoeira foi inventada no Brasil, com uma série de golpes e toques comuns a todos os que a praticam e que os seus próprios inventores e descendentes, preocupados com o seu aperfeiçoamento, modificaram-na com a introdução de novos toques e golpes, transformando uns e extinguindo outros, associando a isso o fator tempo que se incumbiu de arquivar no esquecimento muito deles e também o desenvolvimento social e econômico da comunidade onde se pratica a capoeira. (REGO, 1968, p.31 e p.35)
}

Fica claro, na fala dos mestres e no que a bibliografia traz, que a Capoeira tem sua origem a partir da escravidão misturando-se com aquela existente no país.

Os instrumentos da Capoeira, como retratado por Rego (1968), são exemplos dessa mistura, pois suas origens são diversas, e muitos deles, não se conhecem suas origens, assim como não se sabem por que vias entraram no Brasil.

Exposto acima, um recorte do que a dissertação trouxe de elementos colhidos na entrevista, foram dessa forma, esses itens que deram a base de conteúdo da formação de professores que veremos a seguir.

\section{O Produto: Capoeira como prática pedagógica na Educação Física: uma proposta de formação para professores.}

Como identificado nos dados colhido através de todo processo metodológico acima citado, a Capoeira tem benefícios inúmeros para a formação integral da criança, mas para que esses benefícios possam acontecer, precisamos trazer para o interior da escola o que há de mais pedagógico nessa manifestação, e utilizaremos da transposição didática para tal ensejo.

Trazemos alguns autores como Chevallard (1991), Astolfi e Develay $(1987,1990)$, que discutem sobre o saber científico e as práticas sociais e como legitimá-las como conteúdos escolares. Trouxemos essa discussão, pois a Capoeira não se trata de um saber acadêmico na ótica de Chevallard (1991), mas na ótica dos autores Astolfi e Develay (1990), é possível entender a legitimidade da mesma para trazer seus saberes para o ambiente escolar.

Para Chevallard (1991), o saber científico é aquele criado nas universidades e nos institutos de pesquisa, mas que não está necessariamente relacionado ao Ensino Básico, e o saber a ser ensinado é aquele que está no PCN, na BNCC, dos livros didáticos, saberes científicos que sofreram a transposição didática a fim de democratizar o conhecimento. $\mathrm{O}$ autor também discute a legitimidade das práticas sociais enquanto saberes e, em linhas gerais, assume uma posição que diferencia saberes de práticas sociais. Para ele, o conceito 
de saber diz respeito ao corpo de conhecimento que é legitimado epistemologicamente, legitimação esta que se sobrepõe, geralmente, à legitimação cultural. Nesse sentido, o caráter acadêmico ou semiacadêmico do saber é condição crucial para a ecologia didática. Em sua visão, um saber sábio não pode se autoproclamar um saber, muito menos a escola pode autorizar a si mesma e, menos ainda, os docentes: "O que ocorre na Escola depende, portanto, eminentemente da legitimidade que a sociedade lhe concede e the nega" (CHEVALLARD, 1991, p. 164).

A origem dos saberes, segundo Chevallard (1991), pode dar-se nas práticas sociais; no entanto, nem todo saber chega a ser legitimado e alcança o status de saber sábio. A seu ver, existe uma distância entre um saber e uma prática, e o saber sobre o domínio de uma prática não se constitui necessariamente em um saber desta prática. Para o autor, então, os saberes das práticas sociais só serão considerados efetivamente saberes a partir de sua legitimação cultural, mas principalmente da legitimação epistemológica.

Para estabelecer um contraponto, trouxemos a contribuição de Develay (1987). Ele apresenta sua pesquisa sobre a transposição didática em Ciências Biológicas e, ao trabalhar com o conceito de memória, questiona o processo de escolha do que seria a referência para o estabelecimento do saber sábio. Afirma, assim, que o saber sábio não é um produto de um indivíduo isolado, mas de equipes alocadas em diferentes laboratórios, ou fruto de discussão em congressos e simpósios. Também acentua o fato de que a transposição didática varia de acordo com os diferentes níveis de ensino, havendo várias etapas de transposição de saberes.

Quanto ao fato de se tratar de um estudo sobre um conceito pertencente às Ciências Biológicas, Develay (1987) tece algumas considerações importantes para a nossa discussão. Indica que a transposição didática na área da Biologia conduz a uma série de transformações já destacadas por Chevallard (1991), mas também a um processo de dogmatização, que pode ser explicado por três razões: a primeira, sociopolítica, relativa à visão neutra $\mathrm{e}$ universal que a ciência assume em nossa sociedade; a segunda, institucional, relacionada aos processos de transposição, os quais são determinados pelas instituições e pelos atores envolvidos na seleção dos conteúdos; e, por fim, a epistemológica, que diz respeito às especificidades relacionadas à complexidade e à noção de causa nas Ciências Biológicas. Para Develay (1987), as práticas sociais de referência contribuem para a transposição didática e devem ser consideradas, segundo o esquema:

No livro A didática das ciências, de Astolfi e Develay (1990), os autores propõem uma reflexão epistemológica que examine a estrutura do saber ensinado; que esteja atenta aos aspectos históricos das ciências, baseada na ideia de ruptura e obstáculo; que promova a relação entre epistemologia e didática.

Sobre o tema da transposição didática, esses autores defendem a existência de uma epistemologia escolar, já que afirmam que na escola o saber sábio sofre uma mudança em seu estatuto epistemológico e, dessa forma, o que se ensina nela não seriam saberes em estado puro, mas sim conteúdos de ensino. Astolfi e Develay (1990), nessa obra, propõem a sistematização da transposição didática, afirmando, porém, que, além dela, outros determinantes pesam sobre a elaboração curricular. São eles as práticas sociais de referência, 
os níveis de formulação de um conceito (nos planos linguístico, psicogenético e epistemológico) e as tramas conceituais.

Tanto Develay em 1987 como Astolfi e Develay (1990) sublinham as influências políticas e sociais e destacam os aportes oriundos das práticas sociais, os quais, além do saber sábio, constituem referências importantes para a transposição didática.

Isso nos faz refletir que a Capoeira é um saber legitimado, podendo então, usar a transposição didática para trazê-la pra dentro do espaço escolar.

Mas a necessidade de se ensinar um conhecimento leva à necessidade de modificá-lo, e essa modificação é chamada de transposição didática. Ao entrarem na escola, os objetos de conhecimento, que podem ser o Saber científico ou as práticas sociais, convertem-se em objetos de ensino, isto é, em conteúdo curricular. Para tal, é preciso, então, modificar o saber para este se transformar em objeto de ensino ensinável, ou seja, em condições de ser aprendido pelo aluno.

\section{A constituição da formação}

A proposta de formação em Capoeira para professores tem por objetivo o desenvolvimento educacional docente de professores de Educação Física para o desenvolvimento de atividades didáticas com a Capoeira, ampliando as possibilidades de inclusão dos conhecimentos teóricos dessa manifestação como conteúdo curricular nas aulas de Educação Física, bem como, dar subsídios para a inclusão dessa prática como modalidade extracurricular nos ambientes escolares.

Para a estrutura da formação, utilizaremos como base a teoria de situações didáticas e os dados categorizados na pesquisa.

A Teoria das Situações Didáticas tem suas origens nas propostas de Brosseau (1986) e parte do princípio de que cada saber ou conhecimento pode ser determinado por uma situação entendida como uma ação entre duas ou mais pessoas. Nessa perspectiva, para resolver uma dada questão, o aprendiz deverá recorrer a conhecimentos já sabidos, que podem ter sido aprendidos em qualquer ambiente que corresponda à expectativa do problema em ação.

Contudo, é imprescindível que o professor não apresente soluções para as propostas sugeridas, pois o aluno deverá pensar, agir, refletir sobre a ação e validar os argumentos usados para sustentar as suas respostas. Para tanto, precisamos que o aluno seja capaz de vasculhar a mente à procura de conhecimentos já adquiridos e usá-los na situação dada.

A Teoria das Situações Didáticas (TSD) visa à criação de alunos autônomos, reflexivos, ativos e argumentativos, e essas situações foram batizadas por Brosseau (1986) por situações Adidáticas. É importante, porém, salientar que não há como separar as situações adidáticas das situações didáticas, pois uma faz parte da outra e se complementam.

Essa teoria nos traz Etapas que ajudam na compreensão de sua aplicação.

A etapa da Ação está relacionada ao momento das tomadas de decisões, a prática do saber. É aqui que surgem os conhecimentos dos modelos basilares.

A Formulação é o momento em que os alunos formulam suas estratégias e explicitam-nas verbalmente, recorrendo à ação anterior, tendo consciência da situação e assumindo uma posição em relação a ela. 
Na Validação existe a demonstração dos argumentos utilizados na resolução do problema, os alunos não só devem comunicar uma informação como também precisam afirmar que o que dizem é verdadeiro dentro de um sistema determinado.

E, por fim, a fase de Institucionalização que é o momento onde todos os procedimentos adotados pelos alunos no decorrer da situação problema, desde a ação até a validação, são devidamente registrados e organizados com a ajuda do professor. É onde o saber tem uma função de referência cultural que extrapola o contexto pessoal e localizado. O professor seleciona questões essenciais para a apropriação de um saber formal a ser incorporado como patrimônio cultural.

Nessa proposta, os professores serão os alunos, e o formador, o mediador da situação didática.

A formulação de nossas proposições surgiu a partir do que investigamos diante das falas dos Mestres de Capoeira e categorizamos em 3 grandes eixos: Aspectos integrativos das dimensões humanas da Capoeira e Formação Integral do sujeito, que subsidia os professores em conceitos sobre os aspectos integrativos das dimensões que constituem o ser humano que a capoeira oferece. A roda de Capoeira e a materialização das dimensões do sujeito, com conceitos que evidenciam a Roda de Capoeira como um espaço capaz de integrar as dimensões que compõem o ser humano. E a Musicalidade e a historicidade da Capoeira, que caracterizam a identidade do povo brasileiro e evidencia a importância da música nesta manifestação e a relação que ela tem com a história do povo negro no Brasil, aspecto esse revelador da cultura brasileira.

Assim, adotaremos a Roda de Capoeira como a situação problema inicial, pois foi nela que identificamos a possibilidade de formação integral do sujeito. É na roda que o sujeito acessa todas as suas faculdades cognitivas, físicas, emocionais, sociais e culturais.

Encontramos na Roda de Capoeira o momento de ação e formulação da teoria das Situações Didáticas. Nela, veremos todos os conhecimentos dos envolvidos na formação para que daí comece o processo de institucionalização desses saberes. A Roda de Capoeira será o "start" para entender toda a complexidade dessa manifestação, identificada nesta pesquisa.

Nessa situação problema o mediador vai disponibilizar no espaço instrumentos utilizados na capoeira e propor a seguinte consigna: "Vocês deverão realizar uma roda de Capoeira da forma que acham ser tal manifestação".

Após a experiência de formar uma "Roda de Capoeira", organizada apenas com os conhecimentos advindos dos participantes (fase da ação, formulação e validação),esperamos trazer para a institucionalização os conceitos encontrados nesta pesquisa, que poderão ser discutidos através de novas situações problemas em que daremos exemplo para cada categoria que construímos nesta pesquisa.

Outro conceito importante trazido pelos mestres de Capoeira (além da Roda de Capoeira) é o da historicidade. Todos afirmam que esse fator influi diretamente no reconhecimento da identidade do povo brasileiro, traz a história do país e do povo negro escravizado no Brasil.

Para propormos um aprofundamento sobre esse tema, utilizamos como sugestão a própria prática dos mestres entrevistados, que nos relatam ser nas músicas, nas letras das cantigas, assim como nos instrumentos que compõem a Capoeira, o acesso à história da Capoeira e, consequentemente, do povo negro que a criou. 
A sugestão para introduzir esses conceitos é de que se criem uma cantiga de Capoeira que conte a história da escravidão no Brasil. Nessa situação problema é possível introduzir reflexões acerca do papel histórico do povo negro no Brasil e questões atuais como o Racismo.

Dentro desta mesma vertente, podemos sugerir, como uma prática mais próxima da realidade infantil, uma brincadeira de Jóquei-pô, onde participantes da formação deverão substituir os elementos da brincadeira tradicional pelos elementos que motivaram os negros escravizados a inventarem a Capoeira.

Para a aprendizagem dos movimentos típicos da Capoeira, os mestres não foram específicos, mas trouxeram a importância da Ginga como elemento da negaça, da mandinga, da malícia que é uma característica essencial da Capoeira.

Para a compreensão da dimensão da ginga da Capoeira, podemos propor como situação problema, que, de olhos vendados, os participantes escutem os sons disponibilizados e "ginguem" na cadência de cada ritmo. À medida que eles vão se familiarizando com os sons e se deixando levar por eles, é que o conceito prático da ginga poderá ser inserido.

Nesse sentido, proporemos, para iniciação aos movimentos típicos da Capoeira, divididos em movimentos defensivos e ofensivos, basicamente, que realizem os movimentos a partir de uma descrição escrita ou falada, para que pensem o movimento e o realizem sem interferência ou referência do formador. Essa ação se constituiria a situação problema para as movimentações de corpo da Capoeira.

Propor uma situação problema para o aprendizado dos instrumentos musicais da Capoeira pode ser uma estratégia instigar os participantes a emitirem sons que correspondam aos escutados como referência. Eles escutam um toque do berimbau e realizam o que ouviram. Nessa realização, temos as etapas de ação, formulação e validação, e à medida que vão à busca de como chegar o mais próximo do som, teremos a institucionalização, com conversas, reflexões acerca do som e novas tentativas.

O Jogo da Capoeira já é, por si, só uma situação problema, pois se defender e atacar constituem um problema a ser solucionado corporalmente. Refletir sobre as possibilidades de ataques e defesas podem constituir a institucionalização do jogo, pois se buscam formas mais eficientes de jogar com o outro.

É importante que após todas essas situações problema realizadas, visite-se novamente a situação inicial que é a Roda de Capoeira que vai instigar a busca de superações e novos aprendizados.

Após toda essa vivência, os participantes da formação deverão ser capazes de identificar na Capoeira seus potenciais de formação integral do Sujeito, identificando os princípios da Educação Integral, que serão também incorporados nas reflexões da própria prática da Capoeira.

Para tal formação é preciso tempo e dedicação de todos.

Espera-se que após vivenciar todas as situações problemas expostas aqui, os participantes consigam ter um breve referencial prático da Capoeira e que façam uso de tais estratégias em sua prática pedagógica.

É importante explicitar que tal formação é exclusiva como estratégia pedagógica para aplicação da Capoeira como conteúdo da Educação Física Escolar. A Capoeira é uma manifestação que quanto mais se aprende mais teremos que aprender sobre ela. Volto a dizer 
que não é algo que possa apenas buscar e compreender. É algo para vivenciar, experienciar, absorver, digerir, encarnar corporalmente.

\section{CONSIDERAÇões FINAIS}

Com base nas mensagens dos sujeitos entrevistados, nas discussões e reflexões da bibliografia trazida à luz desta pesquisa pudemos perceber a Capoeira como possível promotora de formação integral do sujeito, o que foi nosso debate central, e a teoria da complexidade foi o que nos ancorou epistemologicamente na busca de respostas para nosso problema de pesquisa.

Conseguimos extrair das entrevistas feitas com mestres de Capoeira da Região do grande ABCDM (abreviação das cidades que compõe a região do Grande ABCDM- Santo André, São Caetano, São Bernardo, Diadema e Mauá), região onde a pesquisa foi produzida, conceitos que convergem sobre aspectos que promovem o desenvolvimento integral do Ser Humano.

Esses conceitos encontrados, que nos trazem a preposição de que a Capoeira pode auxiliar na formação integral do Sujeito, estão na interação entre os elementos que a compõem. Os pontos encontrados.

Os aspectos integrativos das dimensões humanas da Capoeira e Formação Integral do sujeito possibilitou-nos refletir sobre os aspectos integrativos que a Capoeira oferece no desenvolvimento das dimensões humanas, identificadas como a ligação entre os elementos que compõem a Capoeira que são o jogo, a música, os instrumentos, e algo que ocorre só na roda de Capoeira, a interação entre todos eles e as pessoas que constituem a Roda.

A discussão sobre a roda de Capoeira e a materialização das dimensões do sujeito nos possibilitou entender a Roda de Capoeira e suas especificidades como uma forma de integrar as dimensões humanas.

A Roda de Capoeira transcende o fazer superando o jogar, o cantar e o tocar. É sentir a Capoeira nas entranhas, é materializar a emoção, a expressão, a cultura, as individualidades e as generalidades a partir de uma sinergia que só ocorre na Roda de Capoeira, pois tudo que se faz na Capoeira converge para ela. Treina-se, aprendem-se movimentos, aprende-se a tocar os instrumentos, aprende-se a cantar as cantigas para que a Roda de Capoeira aconteça na sua plenitude, na sua complexidade.

Os aspectos relacionados à musicalidade e a historicidade da Capoeira nos auxilia a refletir sobre possibilidades de superação de conteúdos eurocêntricos, elitistas e esportivistas presentes na prática da Educação Física. A musicalidade da Capoeira foi destaque porque é o diferencial dessa manifestação luta-dança-jogo-esporte. É o que faz a ancestralidade da Capoeira estar presente em cada roda, em cada movimento. O ritmo e a música compõem cada defesa e cada ataque à medida que se integram aos jogadores, quase que em um transe, fazendo sentir a história do povo negro no Brasil.

A identidade do povo negro, do povo brasileiro, vive na Capoeira e revive nas rodas de Capoeira que se constituem através das músicas, dos instrumentos, da interação entre o jogo, a música, o ritmo, interação de todos esses elementos com a história da nossa sociedade e o saber pessoal de cada sujeito que faz parte da roda. 
A nosso ver, é essa interação que traz na Capoeira a possibilidade de integralidade das dimensões humanas apresentadas pela teoria da complexidade (MORIN, 2001, 2003), pela ideia de formação do sujeito integral e pela Educação Integral, caracterizada por uma visão de Educação que leva em conta a formação plena do sujeito, considerando o sujeito constituído pelas dimensões intelectual, física, emocional, social e cultural, e não mais uma modalidade de ensino.

A Educação Integral se dará quando o professor for capaz perceber o seu aluno como um Ser que se constitui através de múltiplas dimensões, dotado de experiências e saberes, e a Capoeira auxilia nessa compreensão, uma vez que possibilita uma prática pedagógica que dê sentido a cada ação, onde a ação, na roda de capoeira, faz com que exista uma integração do "homem consigo mesmo, do homem com o mundo e do homem com os outros"(FEITOSA, 1999), que passa, assim, a configurar-se como Motricidade Humana.

A Roda de Capoeira, no sentido do "homem consigo mesmo", está relacionada à individualidade do sujeito, ao aprender, ao compreender e ao superar as dificuldades ou motivações encontradas no universo da Roda de Capoeira como a ação de jogar, cantar e tocar. A Roda de Capoeira, no sentido do "homem com os outros", está relacionada com as ações subjetivas que a ética da Capoeira propõe como respeito ao outro, jogar com o outro, cooperar nas tarefas da roda, entre outras. Já o sentido de "o homem com o mundo" está diretamente ligado a toda produção histórica e cultural do povo negro escravizado no Brasil, que encontramos na Capoeira e que se materializa a cada Roda de Capoeira, narrando a história do povo brasileiro.

Na busca de uma Educação Física que vá ao encontro da visão de Educação Integral, a Ciência da Motricidade Humana, que em sua "essência é o sentido, a significação, a intenção" (SERGIO, 1996, p.24), demonstra ser um pressuposto teórico significativo para a atuação pedagógica do professor de Educação Física na escola, assunto esse para os intelectuais dessa Ciência, pois não foi intenção desta pesquisa caminhar por essa discussão, apesar de considerarmos tal teoria como relevante para a área.

Contudo, entendemos que a Capoeira não é algo que possa apenas buscar, compreender. É algo para vivenciar, experienciar, absorver, digerir, encarnar corporalmente. Para tanto, é necessário compreendê-la e senti-la na sua complexidade.

É importante ressaltar que o papel da Capoeira na busca da formação integral do sujeito só é possível se sentida/vivida. Acreditamos que a somente a leitura sobre a Capoeira não torne possível trazê-la para a escola com todas as possibilidades pedagógicas que essa manifestação brasileira pode oferecer. Por isso, o produto desta pesquisa descrito a seguir é uma formação docente com o intuito de mostrar um caminho possível para o professor sentir e viver a Capoeira e poder levá-la para dentro da escola na sua completude.

\section{REFERÊNCIAS}

ABIB, P.R.J. Capoeira Angola: cultura popular e o jogo dos saberes na roda. Dissertação (doutorado em Ciências Sociais aplicadas a Educação) Faculdade de Educação, UEC, São Paulo, 2002. 
ALVES, F.S. O Corpo em movimento na Capoeira. - Tese (Doutorado)- Escola de Educação Física e Esportes, Universidade de São Paulo, São Paulo, 2011. Disponível em dói: 10.11606/T.39.2011.tde-30012012-150556. Acesso em: 2018-09-18.

ALVES, F.S. O encontro com a capoeira no tempo da vadiação. Revista Movimento, Porto Alegre, v. 19, n. 02, p. 277-300, abr/jun de 2013. Disponível em https://seer.ufrgs.br/Movimento/article/viewFile/30542/25264 Acesso em: 2018-09-18.

ARRUDA, E. O. Capoeira, corpo e educação física: por uma pedagogia corporal e humanista. $1^{\mathrm{a} e d .}$ Curitiba, PR: CRV, 2014.

ASTOLFI, J.P., DEVELAY, M. A didática das ciências. Campinas: Papirus, 1990.

BARDIN, L. Análise de conteúdo. Lisboa: Edições. 1977.

BRASIL. Ministério da Educação e do Desporto/ Secretaria de Educação Fundamental. Parâmetros Curriculares Nacionais.v.10. Brasília: MEC/SE, 1998.

BRASIL. Ministério da Educação e do Desporto/ Secretaria de Educação Fundamental. Base Nacional Comum Curricular. Brasília: MEC/SE, 2017. Disponível em http://basenacionalcomum.mec.gov.br/, acesso em 2018-01-21.

BROUSSEAU, G.Fondements et Méthodes de la Didactique des Mathématiques. Recherches em Didactique des Mathématiques, Grenoble, v. 7, n. 2, p. 33-116, 1986.

BROUSSEAU, G.Introdução ao estudo das situações didáticas: conteúdos e métodos de ensino. São Paulo. Ática, 2008.

CAMPOS, H. Capoeira na Escola, Salvador, EDUFBA, 2001.

CAMPOS, H. Capoeira Regional: a escola de Mestre Bimba- Salvador. EDUFBA, 2009.

CAPOEIRA, N. Capoeira: os fundamentos da malícia. 4. ed. Rio de Janeiro. Record, 1998.

CHEVALLARD, Y. La transposición didáctica: del saber sabio al saber enseñado.Buenos Aires, Aique, 1991.

DARIDO, S.C.; RANGEL, I.C.A.Educação Física na escola: implicações para a prática pedagógica. Rio de Janeiro. Guanabara Koogan, 2005.

DARIDO, S.C.; RANGEL, I.C.A. Para Ensinar Educação Física: Possibilidades de Intervenção na escola. Papiros, Campinas, $7^{\mathrm{a}}$ edição, 2013. 
DAOLIO, J. Educação física e o conceito de cultura- Campinas, SP: Autores Associados, 2004.

DEVELAY, M. A propos de la transpositiondidactique en sciencesbiologiques. Revue Française de Pédagogie, nº 80, juillet-septembre, 1987.

FALCÃO, J. L. C. Para além das metodologias prescritivas na Educação Física: a possibilidades da capoeira como complexo temático no currículo de formação profissional. Revistar Pensar v. 7 n.2 -Florianópolis- SC- 2004- https://www.revistas.ufg.br/fef/article/ view/93/2376 acesso em 2018-09-20

FALCÃO, J. L. C. A escolarização da capoeira. Royal Court, Brasília-DF: 1996.

FALCÃO, J. L. C. Aspectos do desenvolvimento da capoeira: Transnacionalidade, resistência cultural e mobilidade. Criar Educação - PPGE - UNESC v. 5, nº1, Criciúma, janeiro/Junho 2016.file://C:/Users/Casa/Downloads/2457-7448-1-SM.pdf acesso em 2018-12-09

FEITOSA, A. M. A ciência da motricidade humana (C.M.H.). In: SÉRGIO, Manoel et al. O sentido e a ação. Lisboa: Instituto Piaget, 1999.

FRANCO, M.L.P.B. Análise de conteúdo. Série pesquisa. São Paulo, Líber livro, 2008.

FREIRE, J. B. Educação de corpo inteiro. São Paulo, 3 ed., Scipione, 1992.

GUARÁ, Maria F. Rosa. É imprescindível educar integralmente. Cadernos Cenpec: Educação Integral, n.2, São Paulo: Cenpec, 2006.

KUNZ, E.; CARDOSO, C. L.; FALCÃO, J. L. C.; MONCINI, L.; SARAIVA, M. C.; SOUZA, M. Didática da Educação Física. Rio Grande do Sul: Unijuí, 1998.

MIZUKAMI, M. G. N. Ensino: as abordagens do processo. São Paulo: EPU, 1986.

MORAES, M. C. O Paradigma Educacional Emergente. Campinas- Sp: Papirus, Coleção Práxis, 1997.

MORIN, E.A Cabeça bem feita - Repensar a reforma, reformar o pensamento,Bertrand; Edição: 23, 2000.

MORIN, E. Introdução ao pensamento complexo. 1. ed. São Paulo: Instituto Piaget; 2003.

MORIN, E. Os setes saberes necessários á Educação do Futuro. 9. ed. São Paulo: Cortez; Brasília, DF: Unesco, 2004. 
NEGRÃO, R. F. Origem temporal da expressão "educação física" e sua trajetória histórica- uma contribuição. São Paulo, Plêiade, 2008.

REGO, W. Capoeira Angola: um ensaio sócio-etnográfico. Salvador. Itapuã,1968.

REIS, L.V.S. O mundo de pernas para o ar: a Capoeira no Brasil. São Paulo, Publisher Brasil, 1997.

REIS, L.V.S; VIDOR, E. Capoeira: uma herança cultural afro-brasileira. $1^{\mathrm{a}}$ ed. São Paulo, Selo Negro, 2013.

SANTOS, L. S. Educação - educação física - capoeira. Maringá. Fundação Universidade Estadual de Maringá, 1990.

SÉRGIO, M. Epistemologia da motricidade humana. Lisboa: Edições FMH, 1996.

SILVA, P. C. C. Capoeira e Educação Física - Uma história que dá jogo...Primeiros apontamentos sobre suas inter-relações. Revista Brasileira de Ciências do Esporte, São Paulo,v. 23, n.1, p.131-145, setembro. 2001.

TAKEGUMA, R. Capoeira Angola: Arte da Liberdade: “cada uma é cada um, ninguém joga como eu...”. Revista Libertárias: São Paulo, v. 1, n.2, p. 74-79, 1997.

TAVARES, C. Educação integral, educação contextualizada e educação em direitos humanos: reflexões sobre seus pontos de intersecção e seus desafios e seus desafios. Acta Scientiarum. Human and Social Sciences. Maringá, v. 31, n. 2, p. 141-150, 2009. DOI: 10.4025/actascihumansoc.v31i2.5436. Disponível em file://C:/Users/Casa/Downloads/ 5436-29138-1-PB.pdf. Acesso em 20/12/2017.

TAVARES, L. C. V.; SILVA, R. M. A Capoeira no contexto histórico nacional. [s.n.] Aracaju, 2000.

TANI et al. Educação Física Escolar: fundamentos de uma abordagem desenvolvimentista. São Paulo, Pedagógica e universitária, 1988.

VIEIRA, L. R.O jogo de Capoeira: cultura popular no Brasil. Rio de Janeiro: Sprint, 1998. ZULU, Mestre. Idiopráxis de Capoeira. Brasília, 1995.

\section{DAdOS DOS AUTORES:}

\section{IVo RIBEIRo DE SÁ}

Doutor em Educação. Professor da Universidade Municipal de São Caetano do Sul, São Caetano do Sul/ SP- Brasil. ivo.sa@uscs.edu.br 


\section{Samila Zambetti dos Santos}

Mestre em Educação. Professora de Educação Física titular das redes municipais de Diadema e São Caetano do Sul. São Caetano do Sul/ SP- Brasil. samilazambetti@gmail.com

Submetido em: 16-5-2019

Aceito em: $13-2-2020$ 